\title{
Studies on Fixed and Fluidized Bed Ion Exchange Column to Treat Wastewater
}

\author{
Majid Farajpourlar ${ }^{1}$, S. Ram Mohan Rao ${ }^{2}$, V. V. Basava Rao ${ }^{3}$. \\ 1,2,3. Department of Chemical Engineering, University College of Technology, Osmania University, \\ Hyderabad-07, India
}

\begin{abstract}
A continuous fixed and fluidized bed study was carried out by using strong-base anion- exchange resin for removal of nitrate from water. The effect of operating parameters, such as flow rate, initial concentration and bed high was studied. Data confirmed that the breakthrough curves were dependent on flow rate, initial concentration and bed high. Breakthrough experiments were carried out to compare breakthrough curves between packed and fluidized beds. Thomas model was applied to experimental data to predict the breakthrough curves and to determine the characteristic parameters of the packed and fluidized bed columns.
\end{abstract}

Key words:nitrate removal; fixed bed; fluidized bed; ion exchange

\section{Introduction}

Increased levels of nitrate in ground water have made many wells unsuitable as sources for drinking water. Nitrate is so toxic, especially to pregnant women and infants, that the USEPA (United States Environmental Protection Agency) standard of $10 \mathrm{mg} \quad \mathrm{NO}_{3}{ }^{-} \mathrm{N} / \mathrm{L}$ or less in drinking water were established for human health(i.e.,[1],[2]). The primary health concern regarding nitrate, $\mathrm{NO}_{3}{ }^{-}$, is that it is reduced to nitrite, $\mathrm{NO}_{2}{ }^{-}$, in the body. Nitrite in turn reactswith the red blood cells to form methemoglobin, which affects the blood's capability to transportoxygen. High intake of nitrate by infants when bottle-fed, can causes a condition known as "blue-baby" syndrome that can be fatal. It is also claimed by some researchers that there exist a correlationbetween exposure to nitrate and the risk of developing cancer (i.e.,[3]).

Several processes have been described for nitrate removal from portable water among which ion exchange and biological denitrification are the only ones considered feasible and practical for full-scale treatment (i.e.,[4]). Nitrate removal from water using ion exchange is economical and convenient and provides a suitable solution for small or medium-sized water treatment plants containing comparably low nitrate level. Ion exchange is the most common process for public water supplies in the United States(i.e.,[1]).

Ion exchange is a chemical treatment process used to remove unwanted ionic species from waste water. As the name implies, ion exchange works byexchanging undesirable cations or anions in solution with less harmful ones(i.e.,[4],[5]).

\section{Modeling of column operation}

Full-scale column operation can be designed on the basis of data collected in laboratory level. Many mathematical models have been proposed in the past for the evaluation of efficiency and applicability of the column models for large scale operations. To design a column sorption process it was necessary to predict the breakthrough curve or concentration time profile and sorption capacity of the sorbent for the selected sorbate under the given set of operating conditions. Many models have been developed to predict the sorption breakthrough behaviour with high degree of accuracy. The Thomas model was used in this study to analyse the behaviour of the selected adsorbent-adsorbate system.

\subsection{Thomas model}

The Thomas model is one of the most general and widely used. The model is applicable in system with a constant flow rate and no axial dispersion, and its behavior matches the Langmuir isotherm and the second-order reversible reaction kinetics. The model hasthe following form: (i.e.,[6]).

$$
\frac{C}{C_{0}}=\frac{1}{1+\exp \left[\frac{k_{T h}}{Q}\left(q_{0} \cdot m-C_{0} V\right)\right]}
$$

Where $\mathrm{km}$ is the rate constant $(\mathrm{L} / \mathrm{mmol} \mathrm{h}), \mathrm{q}_{\mathrm{o}}$ is sorption capacity of the column $(\mathrm{mg} / \mathrm{g}), \mathrm{Q}$ is flow rate $(\mathrm{L} / \mathrm{h})$, $\mathrm{m}$ is mass of the bed $(\mathrm{g})$ and $\mathrm{V}$ is effluent volume (L).

The linearization of above equation:

$$
\ln \left(\frac{C_{0}}{C}-1\right)=\frac{\mathrm{k}_{\mathrm{Th}} \cdot \mathrm{q}_{0} \cdot \mathrm{m}}{\mathrm{Q}}-\mathrm{k}_{\mathrm{Th}} \cdot \mathrm{C}_{0} \cdot \mathrm{t}
$$

From the linear dependence ofln $\{(\mathrm{Co} / \mathrm{C})-1]$ versus $t$, the removal capacity $q$ and rate constant $\mathrm{k}_{\mathrm{Th}} \mathrm{can}$ be 
determined.

\section{Materials And Methods}

\subsection{Ion Exchange Resin}

The ion-exchange resin employed was the $\mathrm{CL}^{-1}$ type INDION NSSR which was a strong base anion exchange resin. INDION NSSR $\left(\mathrm{CL}^{-1}\right)$ was obtained from Ion Exchange Company. The particles are in the shape of almost perfect spheres with an average diameter $0.5 \mathrm{~mm}(500 \mu \mathrm{m})$. The total exchange capacity was about $0.9 \mathrm{meq} / \mathrm{ml}$ of resin.

\subsection{Fixed bed and Fluidized bed systems}

The overall experimental apparatus is depicted in Fig 1. The column was filled with resin and washed with distilled water. Experiments were carried out in a glass column having $2 \mathrm{~cm}$ diameter and $100 \mathrm{~cm}$ high. The resin were regenerated in down/up flow with volume of $5 \% \mathrm{NaCl}$ solution and washed with distilled water. The temperature was maintained at $31 \pm 1^{\circ} \mathrm{C}$.

The bed dynamic capacity can be expressed by the following equation

$$
q_{b}=\frac{V_{b} C_{0}}{V_{s}}=\frac{Q_{v} t_{b} C_{0}}{V_{s}}
$$

Where, $\mathrm{q}_{\mathrm{b}}$ is the amount of solute ion exchange at rough point $(\mathrm{mmol} / 1)$; $\mathrm{t}_{\mathrm{b}}$ is the service time (h) when the effluent concentration reaches at $45 \mathrm{mg} / 1 ; \mathrm{Q}_{\mathrm{v}}$ is the volumetric flow rate $(1 / \mathrm{h})$ and $\mathrm{V}_{\mathrm{s}}$ is the volume of ion resin in the column (1).

In this study the coefficient ofdetermination, $\mathrm{r}^{2}$, was used to test the best-fitting breakthrough through models to theexperimentaldata:(i.e.,[7],[8]).

$$
r^{2}=\frac{\sum\left(\mathrm{C}^{c a l}-\bar{C}\right)^{2}}{\sum\left(\mathrm{C}^{c a l}-\bar{C}\right)^{2}+\sum\left(\mathrm{C}^{c a l}-\mathrm{C}^{e x p}\right)^{2}}
$$

Where $\mathrm{C}^{\text {al }}$ is the concentration obtained from the isotherm model, $\mathrm{C}^{\mathrm{EXP}}$ is the concentration obtained from experiment, and $\bar{C}$ is the average of $\mathrm{C}^{\text {exp }}$.

\subsection{CHEMICAL ANALYSIS}

Nitrates were measured by a UV-Vis spectrophotometer. The absorbance was measured at $220 \mathrm{~nm}$ and asecond reading was taken at $275 \mathrm{~nm}$. This allowed correction for the interferencedue to dissolved organic matter. The difference between the two absorbance measurements was then calculated by the formula(i.e.,[9]).

Abs $220-2 *(A b s 275)$

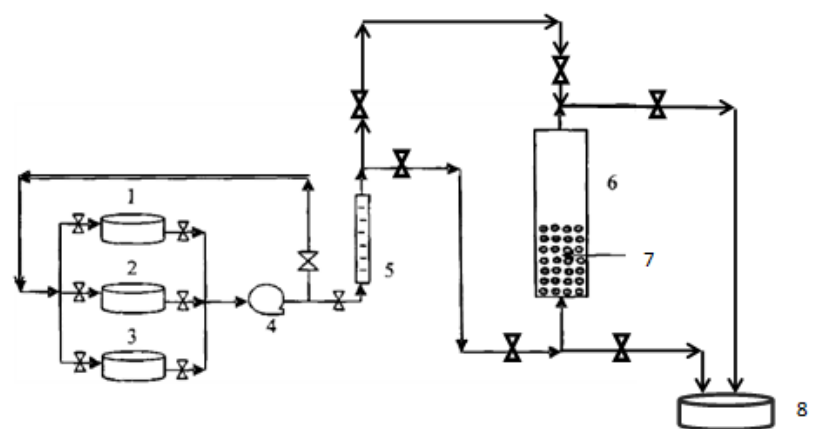

fig 1. Experimental system: (1) $\mathrm{NaNO}_{3},(2) \mathrm{H}_{2} \mathrm{O}$, (3) $\mathrm{NaCL}$, (4)pump, (5)rotameter, (6)column, (7)resin, and (8)effluent

\subsection{Effect of flow rate}

\section{Result And Discussion}

The nitrate solution was pumped in down and up flow mode at 2.34, 3, 3.53 1/hfor fluidized and fixed bed respectively. The results show that flow rate has a major effect on the breakthroughbehavior.Changing the flow rate also influences breakthrough bychangingtheresidence time. Longer residence time gives slower breakthrough and sharper separation. The boundary layer thickness surrounding resin particles becomes smaller as flow rate increases, and thus transfer resistance through the film is reduced at high flow rates. Process throughput is proportional to feed rate.

As shown in table 1 it can be deduced that an increase of the flowratedecreases the breakthrough point ateffluent concentration of $45 \mathrm{mg} / \mathrm{l}$. Table 1 shows the dynamic capacity calculated from 
the column experimental data, it is observed that the flow rate of 2.34 and $31 / \mathrm{h}$ gave the maximum dynamic capacity at inlet concentration of $260 \mathrm{mg} / 1$ for fixed and fluidized bed respectively. Thus, these conditions were considered the optimal operating conditions for these systems. Figures 2, shows the effect of flow rate on the dynamic capacity of nitrate onto INDION NSSR resin at different inlet concentration

Table 1.Breakthrough point and Dynamic capacity at different concentrations and different flow rates, $\mathrm{D}=2 \mathrm{~cm}$, and $\mathrm{h}=6 \mathrm{~cm}$

\begin{tabular}{|l|l|l|l|l|l|}
\hline $\mathrm{C}_{0}(\mathrm{mg} / \mathrm{l})$ & $\begin{array}{l}\text { Flow rate } \\
(\mathrm{l} / \mathrm{h})\end{array}$ & $\begin{array}{l}\text { Breakthrough point } \\
\text { (h)-fixed bed }\end{array}$ & $\begin{array}{l}\text { Breakthrough point } \\
\text { (h)-fluidized bed }\end{array}$ & $\begin{array}{l}\text { Dynamic capacity } \\
(\mathrm{mmol} / \mathrm{l}) \text {-fixed bed }\end{array}$ & $\begin{array}{l}\text { Dynamic capacity } \\
(\mathrm{mmol} / \mathrm{l})-\text { fluidized } \\
\text { bed }\end{array}$ \\
\hline \multirow{3}{*}{260} & 2.34 & 1.3 & 1.2 & 678.5 & 626.3 \\
\cline { 2 - 6 } & 3 & 0.78 & 0.96 & 522 & 642.4 \\
\cline { 2 - 6 } & 3.53 & 0.66 & 0.72 & 519 & 567 \\
\hline \multirow{3}{*}{375} & 2.34 & 0.65 & 0.71 & 489.3 & 534.5 \\
\cline { 2 - 6 } & 3 & 0.45 & 0.53 & 434.3 & 511.5 \\
\cline { 2 - 6 } & 3.53 & 0.39 & 0.46 & 542.8 & 522.4 \\
\hline \multirow{3}{*}{500} & 2.34 & 0.5 & 0.51 & 489 & 512 \\
\cline { 2 - 6 } & 3 & 0.38 & 0.39 & 514.8 & 501.9 \\
\cline { 2 - 6 } & 3.53 & 0.34 & 0.35 & 530 \\
\hline
\end{tabular}
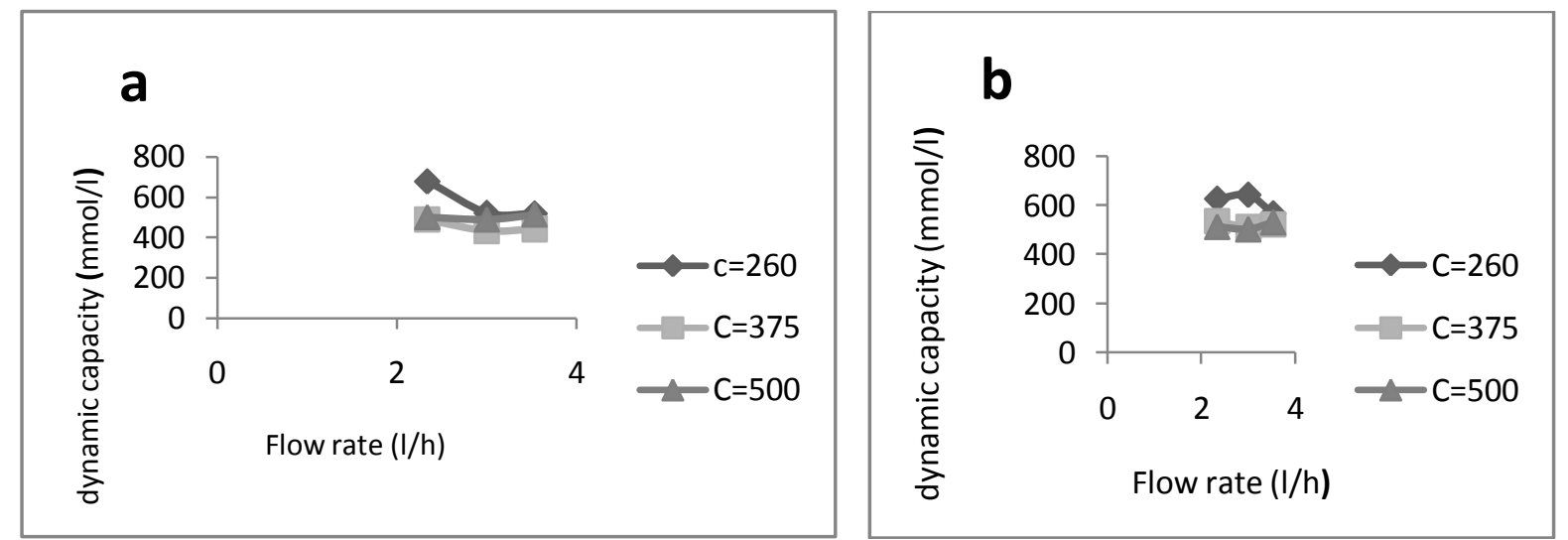

Fig 2 ,Effect of flow rate on dynamic capacity at a different initial concentration-a)fixed bed b)fluidized bed

\subsection{Effect of initial concentration} figure 3.

The change in initial nitrate concentration has a significant effect on breakthrough curve as illustrated in

It shows the resulting breakthrough curves for nitrate at different inlet concentrations. It can be seen from this figure that there was a period of time where nitrate concentration remained zero and then the concentration of the nitrate started to increase. The larger the initial concentration, the steeper is the slop of breakthrough curve and smaller is the breakthrough time. A decrease in breakthrough and the exhaustion time at higher initial concentration may be due to the rapid exhaustion of the sorption sites. In addition, the saturation of the bed is faster at higher nitrate concentration. These results demonstrate that the change of concentration gradient affects the saturation rate and breakthrough time, or in other words, the diffusion process is concentration dependent. Figure 3 show that the effect of initial concentration on the breakthrough curve is the same on fixed bed and fluidized bed 


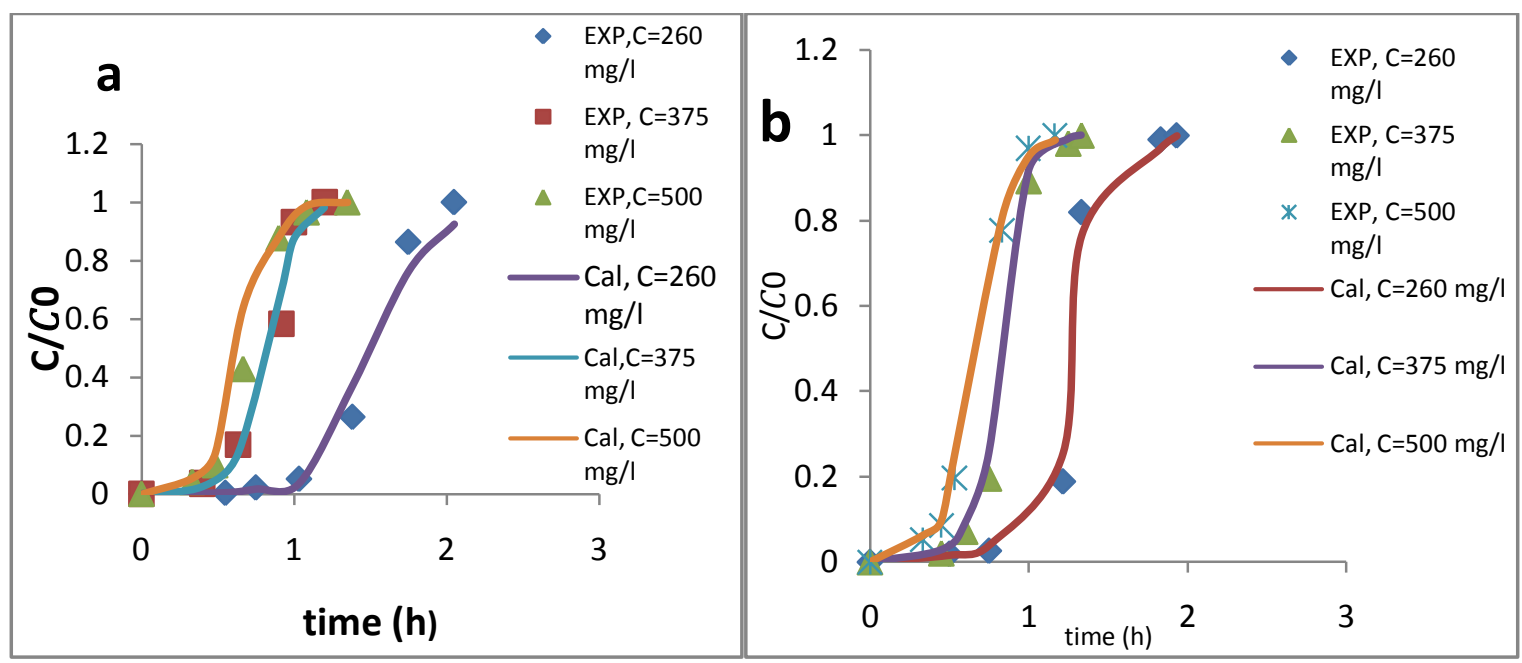

Fig 3, Effect of initial concentration on breakthrough curves at a flow rate of $2.34(1 / \mathrm{h})$ and $\quad$ prediction of Thomas model a)fixed bed , b)fluidized bed

\subsection{Effect of bed height}

Breakthrough curves obtained for the ion exchange of nitrate from its solutions by INDION NSSR resin at different

bed heights, that is, 2,3 , and $10 \mathrm{~cm}$, constant concentration of $260 \mathrm{mg} / 1$, and constant flow rate of 2.34 $1 / \mathrm{h}$ are shown in figure 4.

Figure 4 shows how the breakthrough curves for the removal of nitrate vary with column bed height. The breakthrough curves for the 2 and $3 \mathrm{~cm}$ bed heights reached breakthrough fasterthan the $10 \mathrm{~cm}$ bed height for nitrate removal. The volume of solution treated and the bed service time increased with an increase in bed height. The increase in the volume of solution treated was because of an increase in the sorbent mass (as the bed height was increased) which meant an increase in the ion exchange binding sites available for nitrate ion exchange. Furthermore, an increase in bed height also results in an increase in residence time and hence there is moretime for the nitrate to interact with TULS1ON A-27 resin resulting in an increase inremovalratesand amounts. The breakthrough curves for 2 and $3 \mathrm{~cm}$ bed heights are nearly closed because the bed heights are not sufficient to keep ion exchange process stays for sufficient residence time; therefore, ion exchange is not favorable under these conditions as seen by the premature breakthrough.
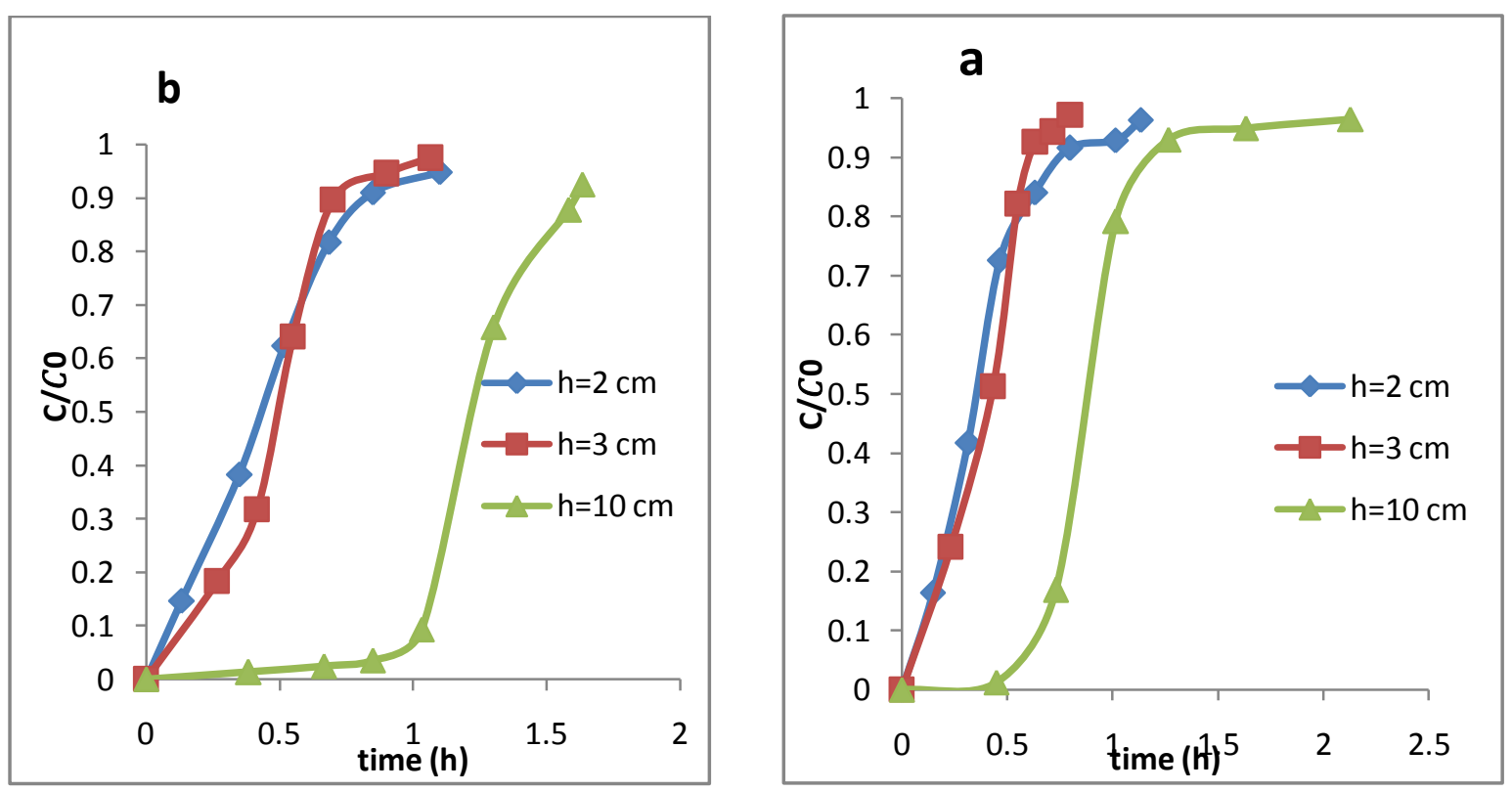

Fig 4, Effect of bed high on breakthrough curves at concentration of $260 \mathrm{mg} / \mathrm{l}$, flow rate $2.34 \mathrm{l} / \mathrm{h}$ and D=2 cm. a)fixed bed and b)fluidized bed 


\subsection{Comparison of breakthrough in packed beds and fluidized beds}

Breakthrough experiments were carried out to compare breakthrough curves between packed and fluidized beds. The amount of resin loading was same in both packed and fluidized beds of each figure. In figure 5, a breakthrough curve in packed beds is slower than in fluidized beds because the flow rate and back mixing rate is not sufficient to decrease the liquid film mass transfer around the resin particles in fluidized bed, which causes decrease in mass transfer resistance while figures 6 and 7 show breakthrough curve in fluidized beds is slower than in fixed beds. The different mass transfer at the early stage of sorption may be related to interstitial velocity. Interstitial velocity, however, is faster in packed beds than in fluidized beds, because of low bed voidage. The higher interstitial velocity in the packed beds will decrease liquid film mass transfer and give slower breakthrough curve than the lower interstitial velocity in the fluidized beds.

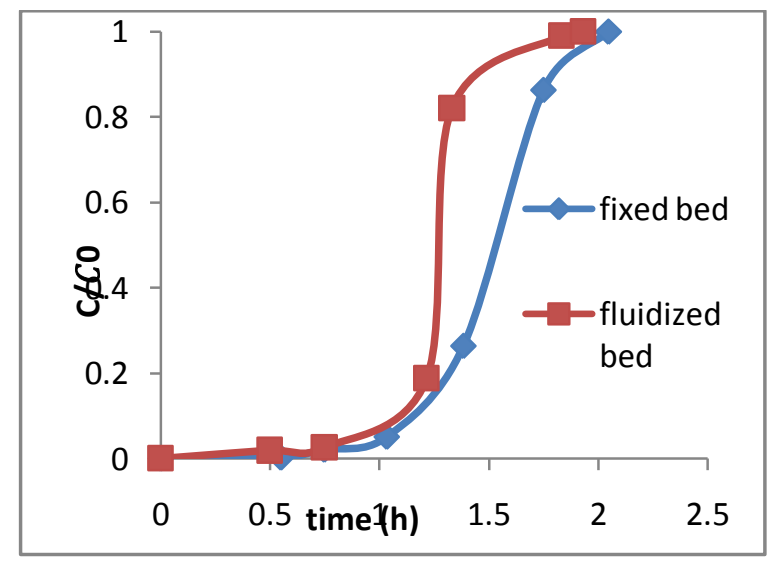

Fig 5.comparison breakthrough curves in the packed bed and fluidized bed at a flow rate $2.34 \mathrm{l} / \mathrm{h}$,concentration of $260 \mathrm{mg} / \mathrm{l}$, and $\mathrm{D}=2 \mathrm{~cm}$

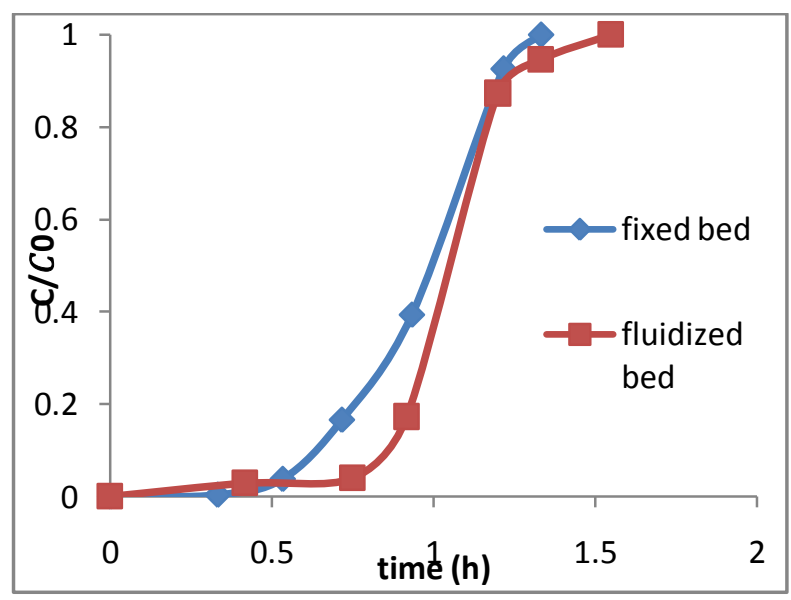

Fig 6.comparison breakthrough curves in the packed bed and fluidized bed at a flow rate $3 \mathrm{l} / \mathrm{h}$, concentration of $260 \mathrm{mg} / \mathrm{l}$, and $\mathrm{D}=2 \mathrm{~cm}$

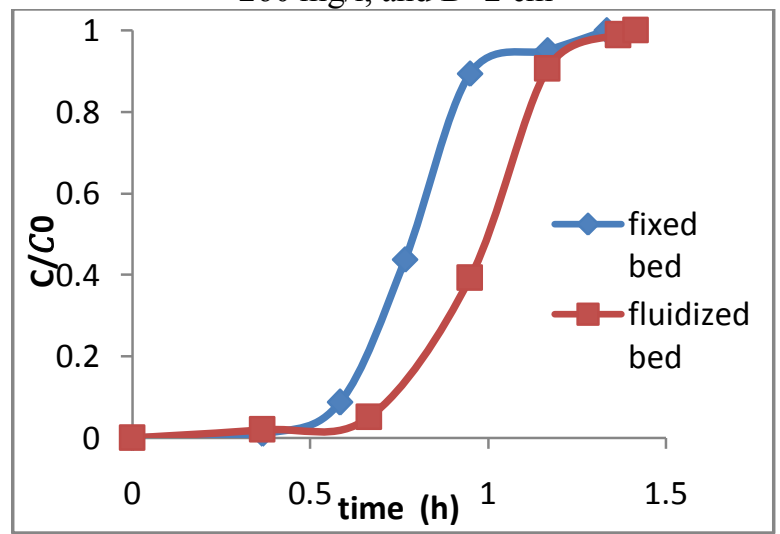

Fig 7.comparison breakthrough curves in the packed bed and fluidized bed at a flow rate $3.531 / \mathrm{h}$,concentration of $260 \mathrm{~m} \mathrm{~g} / 1$, and $\mathrm{D}=2 \mathrm{~cm}$ 


\section{Conclusion}

The breakthrough curves are controlled by several experimental parameters such as the flow rate, initial concentration, and bed high. Data from column studies were described by Thomas model. The Thomas model was successfully found to predict thebreakthrough curves for the fixed and fluidized bed. In the column study, a high breakthrough point which indicatesgood performance of the ion exchange process.Moreover, the breakthrough time increased with decreasing initial concentration, decreasing flow rate, and increasing bed high. Increased dynamic capacity is generally considered beneficial, because it allows given amount of ion exchange resin to ion exchange (bind) larger amount of nitrate. In the other words, this ion exchange procedure will give better capture of the nitrate.

\section{Reference}

[1] Taekyung Yoon, ZangHoshon, Gangchoon Lee, Byunghyun Moon, Byeongil Noh And Nakchang Sung, Korean J. Chem.Eng.,18(2),2001,170-177

[2] KavitaBatheja, A.K. Sinha And Gita Seth, Asian J. Exp.Sci., 23(1),2009; 61-66.

[3] LucijiaFoglar, Laszlo Sipos, NenadBolf,World J MicrobiolBiotechnol 23:2007,1595- 1603

[4] M.Matosic, Mijatovic, and E. Hodzic, Chem. Biochem. Eng. Q. 14 (4), 2000, 141-146

[5] Robert Kunin "Ion Exchange Resin", Rohm and hass company, Philadelphia, Pennsylvania, 1985.

[6] Trgo Marina, MedvidovicNediljkaVukojevic and PericJelena, indian journal of chemical technology 18, 2011,123-131.

[7] Yuh-Shan Ho, Polish Journal Of Environmental Studies 15(1), 2006, 81-86.

[8] K. Vasanth Kumar, K.Porkodi, F.Rocha, Journal Of Hazardous Materials 150 2008, 158-165.

[9] Andrew D. Eaton, Lenore S. Clesceri, Arnold E. Greenberg, M. A. H. Franson. Standard Methods For The Examination Of Water And WastWater, American Public Health.Association (APHA), American Water Works Association(AWWA) \& Water Environment Federation (WEF), 2005. 